\title{
D. Quixote e o Padeiro-mor: cartas de Monteiro Lobato a Antônio Sales
}

\section{Emerson Tin}

Resumo O objetivo deste artigo é analisar a correspondência entre Monteiro Lobato e Antônio Sales, com ênfase nas iniciativas editoriais de Lobato, sobretudo em relação à pretensão de re-editar o romance Dona Guidinha do poço, de Manuel de Oliveira Paiva. Palavras-chave Monteiro Lobato (1882-1948); Antônio Sales (1868-1940); correspondência.

Abstract The aim of this article is to analyze the correspondence between Monteiro Lobato and Antonio Sales, emphasizing Lobato's publishing initiatives, specially in relation to his will to reedit Manuel de Oliveira Paiva's novel Dona Guidinha do poço. Keywords Monteiro Lobato (1882-1948); Antônio Sales (1868-1940); correspondence. 
Ao comprar a Revista do Brasil, em 1918, Monteiro Lobato deu início a um projeto editorial por meio do qual pretendia inundar o país com livros. Anos antes, já o afirmava a Godofredo Rangel, em carta de 16 de janeiro de 1915: "Não há livros, Rangel, afora os franceses. Nós precisamos entupir este país com uma chuva de livros. 'Chuva que faça o mar, germe que faça a palma', já o queria Castro Alves"' Dentro desse plano editorial, a Revista do Brasil serviu como cartão de apresentação e veículo para as experiências editoriais de Lobato. E foi por meio dela que Lobato entrou em contato com intelectuais de vários pontos do país, seja para convidá-los a colaborar na revista, seja para engajá-los diretamente no cotidiano do periódico. Como observa Tania de Luca, "possivelmente, para agilizar a divulgação da revista além das fronteiras paulistas, Lobato criou o cargo de diretor estadual, convidando para exercê-lo pessoas que então desfrutavam de renome no mundo literário"."

É assim que se inicia a correspondência entre Monteiro Lobato e Antônio Sales, ${ }^{3}$ "alma operosa da fundação da famosa Padaria Espiritual, ${ }^{4}$ a que presidiu, como padeiro-mor, sob o nome simbólico de Moacir Jurema, dirigindo, com superioridade, o seu órgão de imprensa, O Pão" 5 Lobato, respondendo a um bilhete que teria recebido do escritor cearense, lança o convite, em carta de 9 de outubro de 1918: "A Revista está organizando um corpo de diretores estaduais. Lembrei-me de convidar no Ceará ao padeiro-mor; mas informado de que ele não residia aí efetivamente, mandei convite ao Papi Júnior, ${ }^{6}$ não recebendo resposta até

1 LOBATO, Monteiro. A Barca de Gleyre. São Paulo: Brasiliense, 1964, t. II, p. 7.

2 DE LUCA, Tania Regina. A Revista do Brasil: um diagnóstico para a (N)ação. São Paulo: Editora da UNESP, 1999, p. 67.

3 As cartas de Monteiro Lobato a Antônio Sales encontram-se depositadas no Arquivo-Museu de Literatura Brasileira da Fundação Casa de Rui Barbosa, no Rio de Janeiro.

4 A respeito da Padaria Espiritual, ver BRITO, Luciana. Padaria Espiritual: um marco na história da imprensa e das artes no Ceará. In: BARBOSA, Carlos Alberto Sampaio et alii. (Org.) Anais eletrônicos da XXII Semana de História "O golpe de 1964 e os dilemas do Brasil contemporâneo". UNESP - Faculdade de Ciências e Letras, Assis, 2004. Disponivel em: http://www.assis.unesp.br/semanadehistoria/PDF/lucianabrito.pdf. Acesso em 08 jan. 2007.

5 Os mortos do Instituto em 1940. Revista do Instituto do Ceará, ano LIV, 1940, p.286-7. Disponivel em: http:// www.institutodoceara.org.br/Rev-apresentacao/RevPorAno/1940/1940-Os_mortos_do_Instituto_em_1940.pdf. Acesso em 08 jan. 2007.

6 Antônio Papi Júnior (1854-1934), escritor e crítico cearense. 
agora"' Afinal de contas, Lobato se empenhava para tornar "de fato a revista do Brasil, e não apenas sulista como tem sido, e também para congregar em torno dela todos os espíritos largos, todos os bons escritores que tenham ideias". Essa carta é um verdadeiro manifesto do editor da Revista do Brasil sobre seus objetivos comerciais e intelectuais:

Preliminarmente, trato de divulgá-la o mais possível, porque a prosperidade comercial da empresa permitirá o selecionamento e o apuro da colaboração. Vai tudo muito bem. Em quatro meses apenas de trabalho já houve um aumento de assinaturas perto de 80o, o que me faz admitir a hipótese de uma vitória completa.

Posta a mira nesse objetivo e fazendo a divulgação da Revista uma ideia fixa - prego metido na cabeça - pę̧o a todos os amigos a cooperação preciosa duma simpatia ativa. A Revista é nossa: que todos, pois, ajudem-na o seu bocado - todos que têm nas veias umas gotas de $D$. Quixote.

Como? Preconizando-a aos amigos, influindo-os a assinarem-na, remetendo o que encontrar digno de publicidade, gravuras antigas, documentos preciosos, notas pitorescas - ou sugestōes, conselhos... Tudo é contribuição e o total de pequenas parcelas avulta.

Para concluir com o pedido: "Conhecedor que é do Norte pode indicar-nos os nomes mais convenientes para o lugar de diretor nos Estados vizinhos?" O mesmo pedido seria reforçado em carta de 31 de janeiro de 1919:

Já temos diretores em 7 Estados. Procuramos agora o homem de Alagoas, Rio Grande do Norte, Sergipe etc. Se pudesse nos indicar nomes idôneos, era favor, porque não conhecemos ninguém desses Estados. Agora que a saída da Revista está regularizada vamos trabalhar na difusão. Dê-nos conselhos quanto ao movimento ai, indique-nos agentes nas melhores cidades, e requisite o material de propaganda que julgar necessário.

7 Correspondência a Antônio Sales, Arquivo-Museu de Literatura Brasileira da Fundação Casa de Rui Barbosa (Col. AS / Cp $139-$ fl. 1-2) 
Unamo-nos nesta campanha para obrigar o Brasil a ler a força. Estamos aqui entusiasmados com a sua boa disposição. Ah! se em todos os Estados encontrássemos um auxiliar da sua ordem!... Meu plano é pôr a Revista num pé de prosperidade que permita fazer dela, logo que as circunstâncias comerciais o permitam, um magazine magnífico, abundantemente ilustrado, como ainda não tivemos outro. E parece que tudo caminha para lá. ${ }^{8}$

Antônio Sales atendeu aos apelos de Lobato, pelo que concluímos da carta de 06 de março de 1919:

Já escrevi ao H. Castriciano (que é um dos dois únicos assinantes que temos no Rio Grande do Norte). Se aceitar, como aceitou o indicado do Amazonas, fica Antônio Sales guindado à posição de Grande Eleitor, ${ }^{10} \mathrm{e}$ uma espécie de superintendente geral para o Norte. Vê-se que o antigo Padeiro inda não perdeu o amor à arte, e continua padeiro quand même. Assim encontrássemos em todos os estados um conselheiro e amigo como você!"

A despeito do empenho de ambos para a divulgação e circulação da Revista entre a intelectualidade de Norte e Nordeste, Lobato desabafaria, em carta de $1^{\circ}$ de junho de 1919:

Os seus gemem projetos quanto à Revista!... Meu caro amigo, não se rale por causa dela. Inda é cedo para uma publicação desta conseguir expansão no Norte. Toda a propaganda aí é de tão pequenos resultados que não compensa absolutamente o esforço. A experiência de um amigo à testa desta publicação ensinou-me muita cousa, e sobretudo a conveniência de circunscrever-lhe o raio de penetração a S. Paulo, Minas, Rio e Sul. Contra a expansão no Norte há: $1^{\circ}$ ) o Correio, cada vez mais infame, cada vez mais gatuno barato, gatuno reles; $2^{\circ}$ ) o caráter provinciano que para o Norte há de

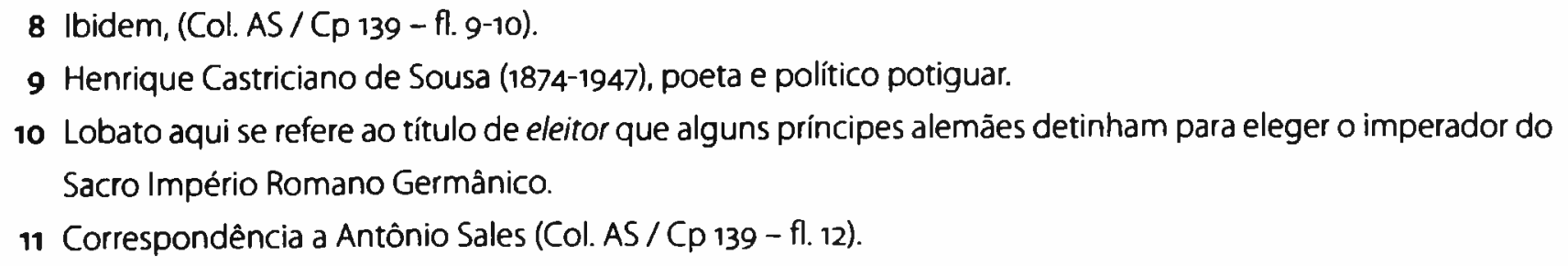


ter uma publicação de S. Paulo; $3^{\circ}$ ) a depressão econômica e o horror nacional à leitura um pouco mais aí do que no Sul. [...] Não insista, meu caro Sales, com ninguém. Ficaremos gratos se inculcar a revista, contando onde se tomam assinaturas, mas nunca insista, nem faça ninguém assiná-la por deferência pessoal para com você. A base da prosperidade econômica da revista consolidá-la-emos por cá. ${ }^{12}$

Lobato exporia seu plano editorial a Antônio Sales na carta de 30 de novembro de 1918:

Meu sonho, na Rev. do Brasil, é fazê-la crescer pelo país inteiro, de modo a ligar todos os espíritos superiores; e pô-la a serviço deles, não só para a publicação das suas obras, como para a divulgação das anteriores, já publicadas. Não procuro reunir nela os medalhões. Entram velhos e novos, contanto que revelem valor. Erro diariamente na apreciação do valor, submeto-me às vezes às injunções de amizade, de simpatia, mas - dado o desconto da contingência humana - procuro fazer dela um instrumento sério e honesto de entrelaçamento mental como não existiu nem existe outro no país. Está no meu programa publicar ensaios críticos sobre as obras injustamente esquecidas, ou mal conhecidas.

Entre as obras injustamente esquecidas ou mal conhecidas estava Dona Guidinha do poço, de Manuel de Oliveira Paiva. Diz Lobato, ainda nessa mesma carta:

Outra novela que merece ser tirada do ostracismo é a $D$. Guidinha do poço. Parece-me que a Revista Brasileira não a publicou integralmente. Com quem estarão os originais? Já escrevi a várias pessoas a respeito, sem resultado. Acho muito bonito aquilo, e queria até editá-la. Faz parte do meu programa uma seção editorial, por um sistema novo, que organizo. Pus, e estou pondo, a Revista em contato com todas as cidadezinhas do Brasil onde haja uma livraria ou papelaria - já fichei 200 - e as obras editadas pela Revista aparecerão nessas 200 casas ao mesmo tempo. Poucos exemplares, 3, 5, 10, conforme a importância do lugar - mas aparecerão, e serão adquiridas pelo menos em parte. Obterei assim uma difusão que ninguém supôs nunca possível. Já fiz

12 Ibidem, (Col. AS / Cp $139-$ fl. 16-17). 
a experiência com o meu livro, e o resultado foi que neste semestre (precisamente 5 meses) tiro dele 8.000 ex. em três edições. ${ }^{13}$

A correspondência, então, passa a girar em torno do livro de Oliveira Paiva. A 2 de janeiro de 1919, afirma Lobato:

Tanto tempo andei atrás de boas informações sobre a Guidinha do poço e afinal me chegam elas inesperadamente e da melhor fonte. Tenho cá a Revista Brasileira, mas com falta dos últimos fascículos onde vem o final da primorosa novela. Desejo muito editá-la em volume porque é um crime tê-la enclausurada numa revista hoje rara. Mas, nesse caso, com quem devo me entender a respeito de direitos autorais? Na qualidade de editor tomo cautelas para evitar futuros aborrecimentos. Preciso de informações a respeito. Fica desde já entendido que o amigo prefaciará a obra e eu me esforçarei por que na fatura material não destoe o livro das excelências da obra. Quero ver se a faço ilustrada. Depois, muita propaganda e reclame. ${ }^{14}$

Ao que parece, Antônio Sales tinha acesso ao romance de Oliveira Paiva, senão aos próprios originais. Nesse sentido, acrescenta Lobato, em 25 de fevereiro de 1919: "Quanto ao romance do Paiva, aqui farei copiar o que falta ao que me vai mandar, e havemos de fazer uma boa edição. Não era conveniente virem esses originais com uma revisão sua? Há de por força haver gatos neles"15

Em 5 de abril de 1919, insiste Lobato: "Vamos ver se me arruma o Paiva. Dá um belo volume, sobretudo se eu puder fazê-lo ilustrado". ${ }^{6}$

A 28 de abril de 1919, referindo-se ao seu Urupês que, após o esgotamento de três edições sucessivas, havia despertado a atenção de Rui Barbosa, então candidato à Presidência da República, que o mencionara numa conferência, intitulada $A$ questão social e política no Brasil, proferida no Teatro Lírico do Rio de Janeiro a 20 de março de 1919, Lobato refletiria sobre o poder da crítica, não sem um certo tom de desânimo

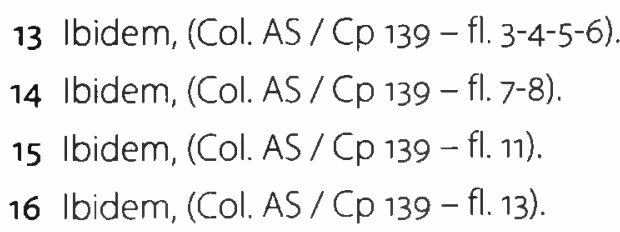


e conformismo, numa observação que poderia facilmente ser aplicável à Dona Guidinha do poço, de Oliveira Paiva, que o editor buscava resgatar ao esquecimento:

O Rui fez-se-me evaporar toda a quarta edição dos Urupês e meter no prelo a quarta, ${ }^{17}$ atingindo assim a onze milheiros em nove meses. Hei de te mandar um da nova edição, um pouco melhor do que as anteriores.

O Jeca popularizou-se horrivelmente. Raro o dia em que não o vejo citado nos jornais. No Rio já está até em música e me consta que em breve surgira à luz da ribalta. O Rio atirou-se com furor uterino aos Urupês devorando 2000 exemplares em 15 dias, esgotando a edição e fazendo pedidos que quase absorvem já a metade da quarta. Que força tremenda é a palavra do Rui! E que sorte a minha! Isto entristece. Tudo na vida depende da chance, tal qual como na roleta. Quantos livros preciosos por aí ignorados só porque os não favoreceu a crítica, porque os tratou com indiferença ou má-fé! Mas é assim a vida e não vale deblaterar contra. ${ }^{18}$

A $1^{\circ}$ de junho de 1919 reforça a expectativa pela chegada de Dona Guidinha: "Quanto à Guidinha que venha, que bem-vinda será." 9 E na carta de 20 de agosto de 1919 há o registro do recebimento do livro e a preocupação de Lobato em relação aos direitos autorais:

Estou com uma carta sua em atraso. Veio com ela a Guidinha. Quanto à propriedade literária, a primeira lei que cuidou disso entre nós foi uma de 1898 estabelecendo o prazo de 50 anos da data da publicação da obra. Ora a Guidinha saiu em 99, já no regime dos 50 anos. Não está, pois, no domínio público, e eu necessitava duma autorizaçāo dos herdeiros para re-editá-la. Dá-se entre nós uma coisa curiosa: a edição de uma obra

17 Evidente equívoco de Lobato. O trecho deve ser o seguinte: "O Rui fez-se-me evaporar toda a terceira edição dos Urupés e meter no prelo a quarta". Efetivamente, a quarta edição de Urupés é de 1919, concluindo, numa tiragem de 4 mil exemplares, o 11 ` milheiro. Ver a respeito MARTINS, Milena Ribeiro. Lobato edita Lobato: história das ediçōes dos contos lobatianos. Campinas, São Paulo, 2003, p. 172 e ss. Tese (Doutorado) - Universidade Estadual de Campinas, Instituto de Estudos da Linguagem.

18 Correspondência a Antônio Sales, Arquivo-Museu de Literatura Brasileira da Fundaçāo Casa de Rui Barbosa (Col. AS / Cp 139 - fl. 14-15).

19 Ibidem. (Col. AS / Cp $139-$ fl. 16-17).

124 - TIN, Emerson. D. Quixote e o Padeiro-mor: cartas de Monteiro Lobato... 
qualquer, literária, é um negócio insignificante, que raro dá um pequeno lucro. Mas se um editor se mete a fazê-la sem autorização do autor ou herdeiros corre o risco de ver cair-lhe em cima um processo, com pedido de gorda indenização. [...] O caso, quanto à Guidinha, está pegando aqui. Não pode o amigo indicar-nos os herdeiros do Paiva? Dirigindo-nos a eles temos esperança de obter a autorização salvaguardadora. ${ }^{20}$

Subentende-se que a preocupação de Lobato em relação aos direitos autorais se dissiparia a partir de uma carta de Antônio Sales a ele dirigida, a que responderia em 3 de outubro de 1919: "Quanto ao negócio da Guidinha, ficamos entendidos. Edito-a logo que puder, independente de mais nada. A sua carta tirou-me os receios" ${ }^{21}$

Após um período de silêncio, uma carta de $1^{\circ}$ de setembro de 1921 repõe a ideia de publicação de Dona Guidinha do poço em discussão:

Não acha que já é tempo de fazermos as pazes? Você está brigado comigo, mas eu estou disposto a pagar na mesma moeda porque continuo a ter Antônio Sales em alta estima e a fazer propaganda dos seus livros sempre que me ocorre oportunidade. Além disso, a vítima da sua turra está sendo o Oliveira Paiva, cuja $D$. Guidinha inda não desisti de vulgarizar. Nem por amor dele você se resolve, caro e neurastênico Sales, a reatar amizade com o Lobato? Vamos lá! Toque nestes ossos e retomemos o caminho do ponto em que a Alemanha nos apartou. ${ }^{22}$

A Guidinha! Só cai no domínio público em 1849 !23 $^{23}$ para dá-la agora só com autorização dos herdeiros. Não sei como resolver isto, pois não os conheço nem sei onde moram. Salva-me, Sales! Descobre-me os homens. O Paiva precisa sair da obscuridade, e sairá, se fizermos as pazes. ${ }^{24}$

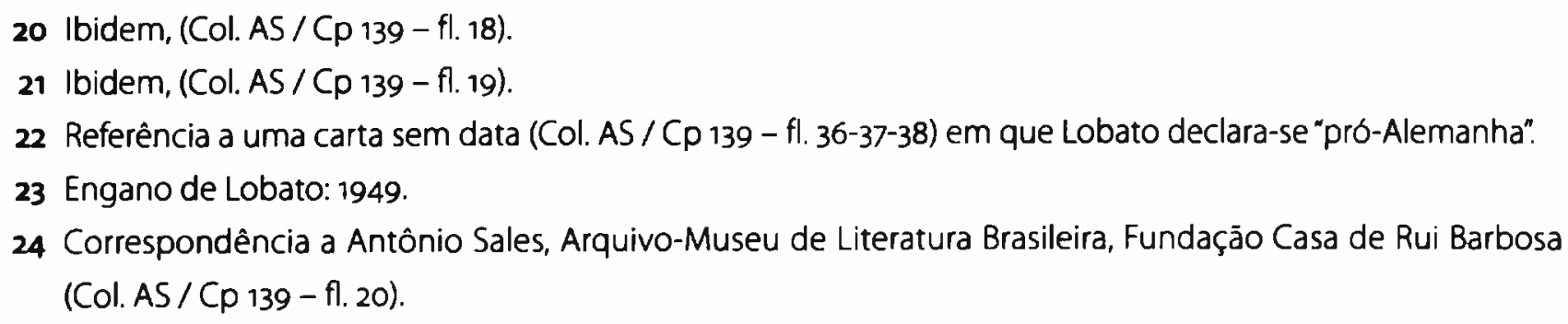


Lobato parece ter enfrentado problemas de várias ordens, pois ainda no final do ano de 1923 o projeto de re-editar Dona Guidinha do poço não se havia concretizado, conforme se depreende da leitura da carta de 30 de dezembro daquele ano:

Recebi a de 18 deste. Podes mandar-me a Guidinha, mas com autorização de alguém da família. Não prometo fazê-la já, porque estou parado, e apenas editando livros escolares, de consumo forçado. $\mathrm{O}$ aperto geral da vida diminuiu tanto a saída dos nossos livros que fechamos a torneira, e estou apenas cumprindo uns contratos urgentes. Câmbio a 4 e 5 ! Que calamidade não é isto para o país! Que sangria que nos vai pondo exânimes, mortos...

Não só o livro fica hoje caríssimo, e com margem insignificante de lucro, como o público não o adquire!....25

Edgard Cavalheiro afirma que "Monteiro Lobato tentou editar D. Guidinha do poço. A correspondência trocada com Antônio Sales, a respeito, é longa, e dela se conclui que a viúva do escritor impediu a concretização dos desejos do editor" ${ }^{26}$ A conclusão de Cavalheiro, contudo, não tem razão de ser, pois em 1923 - data da última carta de Lobato encontrada mencionando o romance - a viúva de Manuel de Oliveira Paiva, Tereza Botelho Oliveira Paiva (1862-1922), já havia falecido ${ }^{27}$ Talvez Lobato tenha deixado de publicar o livro em razão de outros problemas com os direitos autorais, ou então devido aos problemas de sua casa editora que, a partir de 1924, começa a entrar na crise que culminaria na falência em julho de 1925.

Como se lê em A literatura no Brasil, o "romance Dona Guidinha do poço somente em 1952 foi publicado na íntegra e recebeu aplausos da crítica brasileira"28. Infelizmente todos os esforços de Lobato para fazer ir ao prelo essa "primorosa novela" nos anos 1920 foram em vão.

25 Ibidem, (Col. AS / Cp 139 - fl. 27)

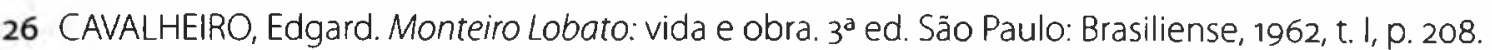

27 Ver PAIVA, Francisco Lopes de. Descendentes de Vicente Ferreira Paiva. Disponível em: http://br.geocities.com/ Ipengenharia200/d1.htm\#i26. Acesso em 08 jan. 2007.

28 COUTINHO, Afrânio (Dir.). A literatura no Brasil, vol. IV. Sāo Paulo: Global, 2002, p. 259.

126 - TIN, Emerson. D. Quixote e o Padeiro-mor: cartas de Monteiro Lobato... 
Mas não só Dona Guidinha do poço estava na mira do editor taubateano: o próprio Antônio Sales seria objeto de interesse para os prelos da Monteiro Lobato \& Cia., como se lê na carta de 18 de maio de 1922:

Tenho editado tanta coisa e nada da tua lavra. Já fizemos as pazes, selemos o tratado com a publicação de uma novela tua. Esse teu silêncio já se prolongou demais. É tempo de provar ao país que viges e viças.

Um romance, uma novela, um livro de contos, queres? As Aves não alcançaram várias edições porque o regime editorial de seu editor é defeituoso. Imprimem o livro, mas não o espalham. Assim não há livro, por melhor que seja, que consiga dilatar o voo. Faze a experiência conosco e verás como tudo muda. ${ }^{29}$

Como argumento para estimular o destinatário, Lobato convocaria, em carta de 9 de agosto de 1922, a opinião de Lourenço Filho sobre o romance e a ideia de re-editá-lo: "Acabo de receber uma carta do Lourenço, na qual me fala com grande entusiasmo de tuas Aves, e propõe-me que as reedite ${ }^{30}$. Ninguém dá mais apreço a elas do que eu, como sabes, e quando quiseres fazê-las revoar conta comigo"."31

Ao que tudo indica, Antônio Sales decidiu-se pela re-edição das Aves. Contudo, a casa editora seria atropelada pelas mudanças na economia, o que adiaria a edição do livro, conforme carta de 8 de novembro de 1923:

29 Correspondência a Antônio Sales, Arquivo-Museu de Literatura Brasileira, Fundação Casa de Rui Barbosa (Col. AS / Cp 139 - fl. 21).

30 O trecho da carta de Manuel Bergströn Lourenço Filho (1897-1970), de julho de 1922, a que se refere Lobato, é o seguinte: "Se tivesse tempo, mandava-Ihe algumas notas interessantes sobre assuntos daqui, inclusive a Padaria Espiritual, de que ainda encontrei 2 representantes vivos: o Rodolfo Teófilo e o Antônio Sales. Este último tem um romance - Aves de arribação, que você deve editar. A $1^{a}$ edição foi limitadíssima, sem reclame, sem nada. Uma edição sua fará o livro conhecido como merece, porque é admirável. O Sales está agora no Rio; ele não me pediu nada, mesmo porque só terminei a leitura do livro há alguns dias. Acredite, porém, Aves de arribação é dos melhores romances nacionais e que você terá lucros cer tos com a edição" (Fundo Monteiro Lobato - CEDAE - IEL/UNICAMP, MLb 3.2.00284Cx6).

31 Correspondência a Antônio Sales, Arquivo-Museu de Literatura Brasileira, Fundação Casa de Rui Barbosa (Col. AS / Cp $139-$ fl. 22). 
Recebi tua última, sobre o Catunda, que já esteve cá e já se foi para o Rio. Simpatizei-me muito com ele e gostei muito do romance que trouxe, mais um belo panorama da região mártir. Infelizmente nada combinei com ele, porque a situação nossa de câmbio a 4 encarece de tal maneira o papel e a impressão que só é possível editar ou coisas pequenas ou livros de consumo forçado. E o romance dele dá $400 \mathrm{pgs!} \mathrm{É} \mathrm{também} \mathrm{essa} \mathrm{a} \mathrm{razão,}$ meu caro Sales, de não termos ainda feito as Aves e Os Brilhantes do Teófilo. ${ }^{32}$ Pegue na pena e faça a conta de quanto fica um exemplar de 400 pgs. com papel a 2800 o quilo. Seria preciso aumentar o preço do livro, o que o público não admite. É uma situação estúpida, e inédita, porque jamais nosso câmbio achatou-se tanto como agora. Quando comecei a editar obtinha papel a 1300 e o preço por pg., para milheiro, era de 5 a $6 \$ 000$. Agora está em 12! e como o câmbio continua a afrouxar é possível que o papel se transforme em matéria tảo cara que só será possível imprimir nele notas do tesouro. ${ }^{33}$

Mas Lobato não conseguiria realizar seu intento. Pareciam proféticas as palavras escritas a Sales em 30 de novembro de 1918:

Como é dificil encontrar os verdadeiros amigos da Revista! Como se erra na apreciação dos homens! Quanta trapaça! Quanto calote! Não obstante a ideia caminha, e hoje uma, amanhã outra, vou congregando em torno da Revista todas as boas vontades em que ela se alicerçará. Quixotada? Que importa! As mais belas coisas do mundo têm saído de D. Quixote.34

\section{Como bem sintetiza Tania de Luca,}

uma conjuntura desfavorável, marcada pela Revolução de 1924, que impôs três meses de inatividade à empresa; pela política deflacionária de Bernardes, com a retração do crédito bancário; pela seca prolongada do ano seguinte, que cortou drasticamente o fornecimento de energia elétrica; acabou por arrastá-lo, em agosto de 1925, à falência. ${ }^{35}$

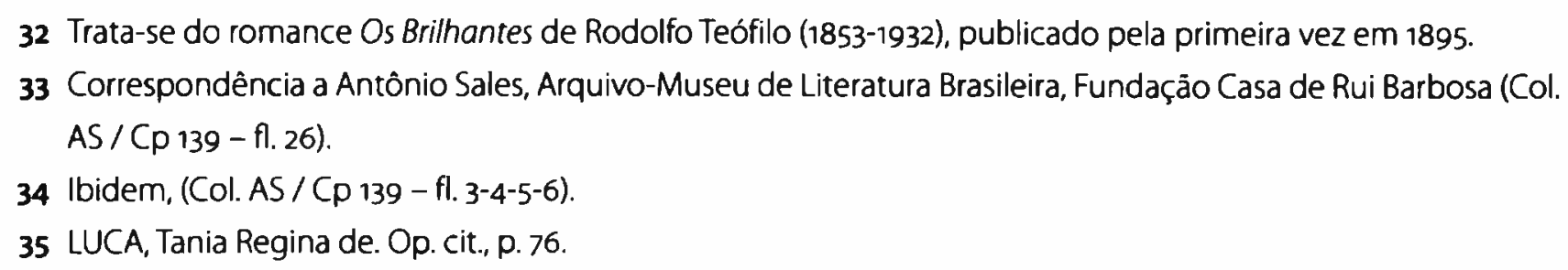


Era o fim da quixotada. Mas não o fim do projeto editorial de Lobato: logo em seguida nasceria a Companhia Editora Nacional e, com ela, finalmente, as Aves de arribação levantariam voo, em 1929, levando a obra do Padeiro-mor aos olhos de todo o Brasil.

Emerson Tin é doutor em Teoria e História Literária pela Universidade Estadual de Campinas. Leciona nas Faculdades de Campinas - FACAMP. Publicações: $A$ arte de escrever cartas [Editora da UNICAMP, 2005] e Quando o carteiro chegou... Cartões-postais a Purezinha, em colaboraçāo com Marisa Lajolo [Editora Moderna, 2006]. 